\title{
The Use of Twitter and Facebook in Teaching Mechanics of Writing to Arabic-Speaking EFL Learners
}

\author{
https://doi.org/10.3991/ijet.v13i09.8457
}

\author{
Abdel Rahman M. Altakhaineh( $\left.{ }^{\bowtie}\right)$, Majed Z. Al-Jallad \\ Al Ain University of Science and Technology, Al Ain, UAE \\ abdelrahman.takhaine@aau.ac.ae
}

\begin{abstract}
This study aims to compare the effect of Twitter and Facebook in teaching 20 Arabic-speaking EFL learners L2 mechanics of writing in an attempt to determine which tool is more effective. We adopted the experimental design of a pre- and post-test to measure the participants' knowledge of English mechanics of writing before and after the treatment, which involved taking part in describing pictures on these two social media networks for two weeks. We divided the 20 participants into two groups: one used Twitter and the other used Facebook to complete the description task. We administered a 100 -word essay task as the pre- and post-test to determine whether the use of Twitter helped the participants improve their knowledge of the mechanics of writing in English more than the use of Facebook or vice versa. The results revealed that the differences between the numbers of errors produced by both groups were not statistically significant even though the group that used Facebook produced a lower number of errors on the post-test. The subsequent semi-structured focus group discussion provided more insight into the answers of both groups on the post-test. The study concludes with recommendations for further research.
\end{abstract}

Keywords-Twitter, Facebook, technology in learning, mechanics of writing, Arabic-speaking EFL learners.

\section{Introduction}

Knowledge of the mechanics of writing is regarded as a very significant aspect of writing composition by EFL learners. This knowledge facilitates the production of a good piece of writing characterised by a cohesive and coherent content that avoids very long sentences, making the comprehension of the written text/essay much easier. In addition, knowledge of the mechanics of writing helps EFL learners produce a well-written essay that reads more smoothly. In this regard, several researchers $[1,2$, $3,4]$ recommended using social media and online material in teaching English. This helps teachers align textbooks curriculum and instruction with new technology. Despite the importance of technology in teaching English as a second/foreign language, little attention has been given to teaching the mechanics of writing to Arabic-speaking EFL learners using social media. In particular, to the best of our knowledge, a comparison between the use of Twitter and Facebook in teaching the mechanics of writing 
in English has not been examined yet. Thus, this study aims to bridge this gap by testing the extent to which the knowledge of mechanics of writing by 20 Arabicspeaking EFL learners, studying at Al Ain University of Science and Technology UAE, can be improved using Twitter and Facebook. In particular, this study examines whether the use of Twitter can enhance the participants' knowledge of the mechanics of writing more than Facebook or vice versa, specifying the main aspects of such mechanics.

\section{$2 \quad$ Literature review}

\subsection{Mechanics of writing}

ESL/EFL teachers usually focus on specific writing skills and mechanics that students need to learn to be able to produce a good piece of writing in L2 [5]. In terms of cohesion (the connection of ideas at the sentence level); firstly, teachers check whether students use grammar correctly when writing. This skill can be considered challenging to students, since they struggle sometimes to remember or apply grammar rules, such as the correct use of word class, the correct use of verb tenses and concord. Secondly, teachers focus on spelling to determine whether students correctly spell words when writing. This is particularly difficult due to the idiosyncrasies that exist in the English writing system, e.g. mute sounds (comb). Finally, teachers check whether students use correct punctuation and capitalisation. Based on our experience as EFL teachers, several students have a hard time remembering or applying the rules for punctuation and capitalisation.

Primarily, coherence is concerned with the rhetorical aspects of writing, including developing the argument and supporting claims using valid reasoning and relevant evidence, and organising and clarifying ideas [6]. These writing skills, including cohesion and coherence, are the main focus of the current study. In addition, since this study examines the effect of using Twitter and Facebook on enhancing students' mechanics of writing in L2, one may wonder here about the different features of these two social media websites. The following are the main differences [7]:

- Twitter focuses on ideas and topics, whereas Facebook focuses on people.

- Facebook allows you to write limitless posts in terms of word count, whereas Twitter limits users to 140 characters per tweet.

- Both Facebook and Twitter provide the feature of using hashtags to group topics or ideas.

- You can search inside of either website for people, topics and organizations.

- Since Facebook allows more options, it is regarded as more difficult to use in comparison to Twitter.

The above features are examined in the current study to determine which website is more effective as far as English writing mechanics are concerned. 


\subsection{Previous studies on the use of Twitter and Facebook in teaching L2 writing}

Researchers in studies that addressed teaching writing have strived to find the most effective methods and approaches to develop L2 learners' writing skills. In this regard, Coffin et al. [1] argue that academic writing is regarded as a primary ingredient in the teaching and learning process in higher education. This is due to the fact that mastering this skill helps EFL learners improve their communicative competence and obtain a good job in the future. Thus, ESL/EFL teachers need to adopt new teaching methods to improve the ability of EFL learners to produce a good piece of writing in L2. According to Melor et al. [2], alternative teaching methods employing computers have recently been adopted in L2 teaching contexts, such as using Facebook groups to teach ESL/EFL learners writing. In particular, in a study conducted by Melor et al. [2], Facebook was employed as a method to teach writing in L2. The results revealed that Facebook can be integrated in writing tasks and activities, since the participants use the features provided by Facebook to acquire new vocabulary through reading the comments written by other students in the group, engaging in discussions related to writing, and peer-assessment. The results also demonstrated that using Facebook can, in fact, help students write their essays via discussing writing tasks in Facebook groups and avoid repeating the same mistakes. In a similar study, Tahir and Aminah [3] investigated whether Facebook can be employed to improve EFL learners' achievement in writing a narrative text in English. The participants who took part in the study were students at the English Department at the University of Iqra Buru. The experiment conducted for the purpose of Tahir and Aminah's [3] study included two cycles and each cycle involved four stages, namely planning, implementation, observation, and reflection. The data was collected through observation and a test. The adopted data analysis methods relied on a descriptive comparative approach. The results showed that the performance of the students improved noticeably and that Facebook can be used as a tool to teach writing a narrative text in English. The results also demonstrated that learning through Facebook had a positive impact on students' motivation to learn in L2. More recently, Kho and Chuah [4] encouraged their students to use Facebook as a platform for ESL discourse exchanges. Following data analysis, the two researchers recommended that ESL/EFL teachers need to supplement their teaching material with online sources and discussion forums using social media websites, such as Facebook, in order to encourage students to engage in interactive lessons, which in turn, improves their English writing and communicative skills. This recommendation was based on an experiment in which the participants engaged actively in exchanging ideas and discussing their viewpoints via Facebook in comparison to traditional teaching methods. In addition to significant improvements in writing, the students were able to acquire new vocabulary through reading the comments written by their peers in the group. Similarly, White [8] conducted a study in which the participants created a discussion group on Facebook and asked students to answer a number of questions and to complete tasks and activities characterised by grammatical complexity and high-level communicative skills weekly. The study lasted for five weeks and the results revealed improvements in both grammar and 
spelling. White [8] also indicated that the students became more involved in the learning process and started to use English to communicate informally in their daily conversations.

With respect to studies on using Twitter in ESL classrooms, Abd Elfatah and Ahmad [9] examined the effect of using Twitter on EFL writing skills and if this social media website has an impact on students' writing skills, including content, ideas, voice, organisation and style. The two researchers adopted the pre- and post-tests experimental design in which two groups participated in the study, namely, treatment and control groups (see [10]). An EFL writing test was used as the data elicitation tool. The pre-test was administered on both groups using a writing test so that their results can be compared before and after the treatment. The treatment group was taught through Twitter, whereas the control group was taught using the traditional teaching methods. Following that, the two groups took the post-test, which was an EFL writing test. The results showed that the treatment group obtained better results on the post-test in comparison with their control group counterpart. The two researchers concluded that teaching writing through Twitter improves students' EFL writing skills and recommended that this method be followed by EFL teachers in various contexts.

On the basis of the above literature, it is clear that studies that examined the most efficient teaching methods to develop L2 learners' knowledge of writing in general and mechanics of writing in particular using social media are needed. No study has been conducted to compare the use of Twitter and Facebook in developing the mechanics of writing by Arabic-speaking EFL learners. Therefore, the current study aims to bridge this gap by answering the following research questions:

1. To what extent can 20 Arabic-speaking EFL learners improve their use of the main mechanics of writing in English using social media websites, namely, Twitter and Facebook?

2. Which of these tools is more effective in developing the participants' English writing skills?

3. Is the performance of the 20 Arabic-speaking EFL learners on the main aspects of writing different or relatively the same and why?

The next section discusses the methodology adopted in the current study.

\section{$3 \quad$ Methodology}

\subsection{Sample}

The sample of the current study included twenty participants, who were enrolled in English 2 Module at Al Ain University of Science and Technology, UAE. The mean age of these participants was 26 years old and they were first year students. These participants were selected because they may have the required skills that enable them to complete the task administered in this study. For the purpose of this study, an equal division of the participants was done classifying them into 2 treatment groups; group 
A and group B. The former group took part in activities in which they were asked to describe pictures using Twitter for two weeks. Conversely, group B took part in activities in which they were asked to describe pictures using Facebook. The rationale behind dividing the participants into 2 groups was to determine whether using Twitter is more effective than using Facebook in improving the participants' knowledge of the mechanics of writing (cf. [10]).

\subsection{The activities}

For two weeks, the group that used Twitter (group A) took part in activities in which they had to describe pictures in one tweet. Such activities were carried out three times for two weeks. The participants were not informed of our intention to examine in the mechanics of writing, since the idea behind the experiment was to ascertain if learners of English as a foreign language can improve their mechanics of writing incidentally while using social media. In group B, the participants took part in the same activities but on Facebook. In these activities, they had to compose a post describing pictures for two weeks. In this study, we created a comparative atmosphere to encourage students to take part in the required tasks. In addition, the students took the tasks they had to complete more seriously, which helped in providing more reliable results.

\subsection{Data elicitation tool and procedure}

A 100-word essay test was administrated to examine the participants' knowledge of the mechanics of L2 writing. With a slight change to the topic of the test, the writing test was employed as both the pre- and post-test to decide if the treatments were effective in enhancing the participants' knowledge of the mechanics of writing (see section 3.2). In the pre-test, the participants were asked to write an essay to describe themselves, whereas on the post-test they were asked to write an essay to describe someone they live up to. The participants took the pre-test at the end of the week before the activities took place, while they took the post-test two weeks later. This was done to make a comparison between the results of the two groups. Of note here is that the errors produced regarding the mechanics of writing that were detected in the pre- and post-tests were grouped and classified as in the following table:

Table 1. The type of error produced by the participants and their numbers

\begin{tabular}{|l|c|}
\hline \multicolumn{1}{|c|}{ Types of error } & Number of errors \\
\hline Spelling & \\
\hline Punctuation & - \\
\hline Grammar & - \\
\hline Parts of speech & - \\
\hline
\end{tabular}

${ }^{1}$ Note that examples of spelling errors vary from misspelling of one word, e.g. swet instead of sweet, compound words goal keeper instead of goalkeeper (see [11, 12]), acronyms, e.g. Fyi instead of FYI (see [13]) among others. 
After administering the post-test, a semi-structured focus group discussion was conducted with the participants in both groups. This type of discussion allows researchers to gain more details about the participants' experience of taking the test and if they encountered certain challenges in completing the writing task. Denscombe [14] argued that semi-structured focus-group discussions can be classified among those tools that enable the researcher to elicit more in-depth information pertaining to the topic under investigation. The participants, during these discussions, feel more comfortable because the interviewer provides them with the chance to discuss open-ended questions and to steer the conversation more freely [14]. Thus, the researcher has less control over the discussion; this flexibility gives the participants the chance to talk more freely about their experience, comparing their performance on the pre-test and on the post-test. During the focus-group discussion, the researchers asked the participants to elaborate on their experience in using Twitter and Facebook to complete the writing task and whether they found these websites useful to practice their writing techniques.

\subsection{SPSS analysis}

A paired sample $t$-test was administered to decide if there is a statistically significant relationship between the two treatment groups, i.e. Twitter and Facebook, as far as their results are concerned on both tests. This type of test compares two means, which makes it suitable for the purpose of this study [15]. Specifically, the observations of the two groups were paired to be examined. This test is called paired because the measurement of each sample is done twice, giving researchers pairs of results [15]. The paired sample $t$-test is commonly used in research papers employing preand post-test analyses such as the one used in the current study. A pre- and post-test were administered to explore the effectiveness of two treatments on the test results of two groups of participants (cf. [16]). The results of this test and its interpretations are presented and discussed in section 4 .

\section{$4 \quad$ Results and discussion}

\subsection{Quantitative results}

The errors produced by the two groups on all types of mechanics of English writing were calculated in order to answer the two research questions, which examine if using social media websites, namely, Twitter and Facebook can improve the ability of the participants to use the main mechanics of writing and which of these tools is more useful. Table 2 below shows that group B, the one that used Facebook outperformed their group A counterparts on the post-test. In particular, members of group B produced a lower number of errors in comparison with group A. Nonetheless, the results showed that the means of errors produced by the two groups on the post-test are lower compared to those on the pre-test as can be observed in Table 2, which shows the total number of errors provided by both groups on the pre-test and the post-test. 
Table 2. Number of errors of the two treatment groups on both tests and types of the mechanics of writing

\begin{tabular}{|l|c|c|c|}
\hline \multicolumn{1}{|c|}{ Type of test } & $\begin{array}{c}\text { Number of errors } \\
\text { produced by group } \\
\text { A (Twitter group) }\end{array}$ & $\begin{array}{c}\text { Number of errors } \\
\text { produced by group B } \\
\text { (Facebook group) }\end{array}$ & Total \\
\hline Pre-test (spelling) & 234 & 212 & 446 \\
\hline Pre-test (Punctuation) & 45 & 49 & 94 \\
\hline Pre-test (Grammar) & 38 & 45 & 83 \\
\hline Pre-test (Parts of speech) & 31 & 25 & 56 \\
\hline Total Number of errors (Pre-test) & $\mathbf{3 4 8}$ & $\mathbf{3 3 1}$ & $\mathbf{6 7 9}$ \\
\hline Post-test (spelling) & 143 & 114 & 257 \\
\hline Post-test (Punctuation) & 31 & 32 & 63 \\
\hline Post-test (Grammar) & 21 & 18 & 39 \\
\hline Post-test (Parts of speech) & 26 & 16 & 42 \\
\hline Total Number of errors (post-test) & $\mathbf{2 2 1}$ & $\mathbf{1 8 0}$ & $\mathbf{4 0 1}$ \\
\hline
\end{tabular}

Concerning the pre-test, the total number of errors produced by the participants in group A, i.e. spelling (234), punctuation (45), grammar (38) and parts of speech (31) and on the post-test spelling (143), punctuation (31),grammar (21) and parts of speech (26) demonstrates that the performance of these participants exhibited a remarkable improvement. Similarly and again on the pre-test, the total number of errors produced by group B, i.e. spelling (212), punctuation (49), grammar (45) and parts of speech (25) and on the post-test: spelling (114), punctuation (32),grammar (18) and parts of speech (16), shows that the participants' results have greatly improved. That is, both groups (A and B) seemed to benefit from using Twitter and Facebook to learn writing in English [3, 4], with more improvement to group B who used Facebook to learn the mechanics of writing. However, a paired sample t-test was employed to help the researchers decide if there is a statistically significant relationship between the number of errors produced by both groups on the post-test. Testing these results enables the researchers to answer the second research question that examines if the treatments, i.e. practicing writing in English via Twitter and Facebook, improve the participants' ability to write in L2. Table 3 below presents the results of this test.

Table 3. Paired sample $t$-test of the differences between both groups on the post-test

\begin{tabular}{|c|c|c|c|c|c|}
\hline Groups & Means & SD & t & df & Sig. \\
\hline Group A (post-test) & 55.25 & 58.64 & 1.5412 & 3 & 0.22 \\
\hline Group B (post-test) & 45.00 & 46.55 & 1.2354 & 3 & 0.22 \\
\hline
\end{tabular}

Table 3 demonstrates that even though there were differences between the number of errors produced by group A and group B (see Table 2), these differences were insufficient to be statistically significant, i.e. $\mathrm{p}<0.05$. This suggests that at least statistically, that there was no relationship between the use of Twitter and Facebook to improve the mechanics of writing in English by the participants. Having discussed the quantitative data, in the remainder of this section, we analyse the errors produced by 
the participants qualitatively, which we obtained through the semi-structured focus group discussion.

\subsection{Qualitative results}

As far as the mechanics of writing are concerned, it is worth pointing out that spelling skills have developed the most, followed by grammar, punctuation and parts of speech, respectively. This is due to the fact that both Twitter and Facebook provide writing enhancement software pragmas that normally check for grammar, spelling, and punctuation mistakes. Based on our observations of the students' comments on each other's posts, it seems that they relied on these programs to give feedback to each other, despite the fact that these programs normally fail in detecting problems related to the use of parts of speech. The students in the current study seem to have utilized these programs to enhance their writing skills. The following are some of the students' essays on the pre-test. Note that the following examples are representative of the errors produced by the majority of the participants on the pre-test:

1. It is great to $b$ a beter maan in the word.

2. she were sick so we visitd her .....

3. $i$ am a good goal keeper and my freind like me ....

4. fyi: mom takes me to the malls everytime I like

5. I'm interesting in swimming and reading...

The above examples show that prior to taking part in the treatment, namely, engaging in activities that included practicing writing through describing pictures on Twitter and Facebook, the participants produced several errors pertaining to spelling, punctuation, grammar and parts of speech. In example (1), the participant clearly had a problem with spelling, e.g. be, beter, maan, and word. In (2), the error produced is related to grammar, more specifically concord, e.g. *she were. The participant also failed to use punctuation in the needed place, i.e. before so. In (3), the compound goalkeeper was spelled inaccurately and the participant failed to capitalise the first person singular pronoun $I$. The participant also failed to use a main verb in the second conjunct. In (4), the acronym was spelled incorrectly or without capitalisation, i.e. *fyi, and the adverbial of time everytime was also misspelled. In (5), the wrong part of speech was used, i.e. interesting instead of interested. These errors may show that the participants had serious problems with the four writing skills, i.e. spelling, grammar, punctuation and parts of speech. Conversely, following the treatment we conducted whereby we asked students to use Twitter and Facebook to complete written tasks describing pictures for two weeks, the number of errors produced by the participants on the post-test decreased noticeably. As mentioned previously, this achievement may be attributed to the writing software programs that detect spelling and grammatical mistakes automatically on these websites. One may look at it differently; arguing that these websites that employ this type of software may help ESL/EFL learners improve their writing skills through time and repeated use, helping them avoid these errors in the future. 
Even though the differences between the numbers of errors produced by both groups on the post-test were not statistically significant, group A produced lower number of errors in comparison with group B. During the semi-structured focus group discussion we conducted with both groups following the post-test, the participants who used Twitter (i.e. group A) explained that Twitter does not provide them with the options found on Facebook. For instance, they indicated that in certain cases, they wanted to write more than 140 characters to convey their idea fully, yet Twitter does not permit that. In addition, Twitter is more concerned with ideas and topics, especially those related to politics and economy, whereas Facebook is more focused on people, making the completion of the target task in the current study easier and the writing itself more flexible.

\section{Conclusion}

This study has examined the use of Twitter and Facebook by 20 Arabic-speaking EFL learners to decide which one of these tools is more effective in teaching the mechanics of writing. This study was conducted using a pre- and post-test to assess the participants' ability to use the mechanics of writing in L2 prior to and following the treatment. An equal division of the participants was done classifying them into two groups. The first one, namely, group A practiced writing on Twitter and group B engaged in writing activities on Facebook. The results show that although both groups have developed their use of the mechanics of writing in English, group B who engaged in writing activities on Facebook has exhibited more improvement in comparison with group A. The results showed that the difference between the numbers of errors produced by both groups were not statistically significant even though group B (the Facebook group) produced a lower number of errors. The use of writing software programs has played a major role in the groups' remarkable achievement. The frequency of using Facebook and the nature of the application itself helped students get more engaged in the activities and enjoying the use of Facebook. On the other hand, the student's attitudes towards the use of Twitter being a place for politicians to announce and share certain news and ideas had negative effects on the results obtained from the participants on the post-test.

Drawing on the above results, the study recommends that English language teachers need to utilise social media to enhance students' L2 writing skills in general, and the mechanics of writing, in particular. Finally, research papers that explore if using social media helps English language learners understand and use figurative language, i.e. metaphors and metonymy $[17,18])$ are also needed.

\section{References}

[1] Coffin, C., Curry, M. J., Goodman, S., \& Hewings, A. (2002). Teaching Academic Writing. Routledge, New York. 
Paper-The Use of Twitter and Facebook in Teaching Mechanics of Writing to Arabic-Speaking EFL...

[2] Melor Md. Yunus, Hadi Salehi, Choo Hui Sun, Jessica Yong Phei Yen \& Lisa Kwan Su Li (2012). UsingFacebook Groups in Teaching ESL Writing, Recent Researches in Chemistry, Biology, Environment and Culture, 75-80.

[3] Tahir, S. Z. B., \& Aminah, A. (2014). Improving Students' Writing Skill Through Facebookat University of IqraBuru. In Conference proceedings. ICT for language learning, 235-241 edited by Pixel. libreriauniversitaria. it Edizioni.

[4] Kho, M. G. W., \& Chuah, K. M. (2015). Encouraging ESL discourse exchanges via Facebook: A study on engineering students. Technology and Innovation Conference.

[5] Byrne, D. (1979). Teaching writing skills. London: Longman.

[6] Rivers, W.M. (1981). Teaching foreign-language skills. Chicago: University of Chicago Press.

[7] Social Media Marketing. (2017) [Accessed online 31 $31^{\text {st }}$ Jan 2018 from: https://webtegrity.com/our-blog/social-media-marketing/whats-difference-betweenfacebook-and-twitter/]

[8] White, J. (2009). The use of Facebook to improve motivation and academic writing. In Proceedings of the Third International Wireless Ready Symposium (pp. 28-32).

[9] Abd Elfatah, M and Ahmad, A. (2015). The Effect of Twitter on Developing Writing Skill in English as a Foreign Language. Arab World English Journal, 2, 134-149.

[10] Altakhaineh, A. R. M. and Zibin, A. (2017). The effect of incidental learning on the comprehension of English affixes by Arabic-speaking EFL learners: acquisition and application. Research in Language, 15(4). 405-423. https://doi.org/10.1515/rela-2017-0023

[11] Altakhaineh, A. R. M. (2016). What is a compound? The main criteria for compoundhood. ExELL, 4(1). 58-86. https://doi.org/10.1515/exell-2017-0007

[12] Altakhaineh, A. R. M. (2017a). Arabic compounds within the cross-linguistic compound taxonomy of Scalise and Bisetto (2009). Lingue e linguaggio, 16(1). 101-118.

[13] Altakhaineh, A. R. M. (2017b). The Linguistic Features of Acronyms in Arabic. SAGE Open, 7(4), 1-14. https://doi.org/10.1177/2158244017746710

[14] Denscombe, M. (2010). The Good Research Guide: For Small-Scale Social Research Projects. $4^{\text {th }}$ edn. Maidenhead: Open University Press.

[15] Hsu, H., \& Lachenbruch, P. A. (2008). Paired t test. Wiley Encyclopedia of Clinical Trials. Chicago https://doi.org/10.1002/9780471462422.eoct969

[16] Ionin, T., \& Wexler, K. (2002). Why is 'is' easier than '-s'?: acquisition of tense/agreement morphology by child second language learners of English. Second Language Research, 18(2), 95-136. https://doi.org/10.1191/0267658302sr195oa

[17] Zibin, A. (2016). On the production of metaphors and metonymies by Jordanian EFLlearners: Acquisition and implications. Topics in Linguistics, 17(2), 41-58. https://doi.org/10.1515/topling-2016-0012

[18] Zibin, A. and Altakhaineh, A. R. M. (2018). An analysis of Arabic metaphorical and/or metonymical compounds: A cognitive linguistic approach. Metaphor and the Social World, 8(1), 99-132. https://doi.org/10.1075/msw.16023.zib

\section{Authors}

Abdel Rahman Mitib Altakhaineh is an Assistant Professor of English language and linguistics at Al Ain University of Science and Technology, UAE, since August 2016. His research interests lie in the areas of morphology, lexical semantics, morphosyntax, sociolinguistics, applied linguistics, discourse analysis, and secondlanguage acquisition. He published research papers in several journals, including: 
Studia Linguistica, Lingua, Acta Linguistica Hungarica, STUF - Language Typology and Universals, Research in Language, Lingue e Linguaggio, Metaphor and the Social World and Sage Open.

Majed Z. Al-Jallad is a Full Professor of curriculum and instructions at Al Ain University of Science and Technology, Al Ain, UAE. He published many research papers in many different national and international journals. He is currently the dean of the College of Education, Humanities and Social Sciences at Al Ain University of Science and Technology.

Article submitted 18 February 2018. Resubmitted 23 March and 28 May 2018. Final acceptance 29 May 2018. Final version published as submitted by the authors. 